-研究报告・

\title{
探讨海南岛生物地理起源上有意义的 一些种子植物科和属
}

\author{
朱 华* \\ (中国科学院西双版纳热带植物园综合保护中心，云南预腊 666303)
}

\begin{abstract}
摘要: 海南岛在始新世时可能连接着越南北部和广西, 后来随着喜马拉雅的隆升及印度支那地质板块向东南的逃 逸, 发生了向东南的移动和旋转, 最终到达了现在的位置。目前这一观点已被正式提出。为进一步探讨该观点, 本 文列举了海南岛植物 5 科 36 属的分布情况。这些类群均显示了云南南部及东南部、广西西南部和海南的分布格局, 并包括了乔木、灌木、藤本、草本各生活型，广泛存在于这些地区的热带植被中。这种分布格局的形成最好的解 释就是广西西南部、海南和越南北部曾存在可能的陆地连接。这些科属非常值得进行深入的分子生物地理、亲缘 地理及遗传多样性等方面的研究，期望这些具有特别地理意义的海南植物科和属的信息能为探讨海南岛的起源提 供依据。
\end{abstract}

关键词：种子植物; 分布; 生物地理起源, 海南岛

\section{Families and genera of seed plants in relation to biogeographical origin on Hainan Island}

Hua Zhu

Center for Integrative Conservation, Xishuangbanna Tropical Botanical Garden, Chinese Academy of Sciences, Mengla, Yunnan 666303

\begin{abstract}
The theory that Hainan Island could have been in contact with northern Vietnam and Guangxi during the Eocene and drifted to its present location by moving southeast with the uplift of the Himalayas and extrusion of the Indochina block was recently suggested. To further discuss the biogeographical origin of Hainan Island, 5 families and 36 genera of seed plants on the island were examined in this paper. These families and genera have species that show a distribution pattern of southern and southeastern Yunnan, southwestern Guangxi, and Hainan in China. Life forms of these taxa include trees, shrubs, lianas and herbs, which are present in various tropical forests in these regions. The logical and reasonable explanation for the distribution pattern is that Hainan Island could have been in contact with northern Vietnam and Guangxi. This paper presents information on these families and genera of biogeographical importance, specifically in relation to the origin of Hainan Island for further studies on molecular biogeography, phylogeography and genetic diversity.
\end{abstract}

Key words: seed plants; distribution; biogeographical origin; Hainan Island

海南岛 $\left(18^{\circ} 10^{\prime} 04^{\prime \prime}-20^{\circ} 9^{\prime} 40^{\prime \prime} \quad \mathrm{N}, 108^{\circ} 36^{\prime} 43^{\prime \prime}-\right.$ $111^{\circ} 2^{\prime} 31^{\prime \prime} \mathrm{E}$ )位于中国东南部, 面积约 $33,920 \mathrm{~km}^{2}$ 。中 部以山地为主, 周边为低地, 最高峰五指山海拔 $1,867 \mathrm{~m}$ 。海南岛具典型的热带气候, 年均温 $23-25^{\circ} \mathrm{C}$, 东部较湿润, 年降水量2,000-2,400 mm, 西部相对
较干燥，年降水量仅 $1,000-1,200 \mathrm{~mm}$ 。

海南岛低地的植被以热带雨林和季雨林为主, 山地主要是山地雨林或山地常绿阔叶林(广东植物 研究所, 1976)。关于海南植物区系的研究已有很多, 一些有代表性的工作如张超常和刘兰芳(1983)、吴

收稿日期: 2017-01-05; 接受日期: 2017-03-20

基金项目: 国家自然科学基金(41471051, 31170195, 41071040)

* 通讯作者 Author for correspondence. E-mail: zhuh@xtbg.ac.cn 
德邻等(1996a, b)、张宏达(2001)等。海南植物名录 显示海南岛有野生种子植物 218 科 1,102 属 3,715 种 (邢福武等, 2012), 杨小波(2013)记录了海南岛野生 种子植物4,596种。总之, 其野生种子植物记录基本 上是清楚的。在海南植物区系中, 仅有7个特有属和 约 $10 \%$ 的特有种，非常低的特有性显示了它的大陆 起源特征(Francisco-Ortega et al, 2010a, b)。在植物 区系分区上海南曾被认为是属于华南地区 (吴德邻 等, 1996a, b), 但实际上它具有明显的热带亚洲亲 缘, 在植物区系分区上被划为印度-马来西亚植物 区(Wu \& Wu, 1996; Zhu \& Roos, 2004; 吴征镒等, 2010; Zhu, 2016)。

古植物学研究显示, 海南岛在始新世时具有亚 热带性质的植物区系和亚热带气候, 处在一个比现 今更北的位置; 在海南发现的冷杉属(Abies)和铁杉 属(Tsuga)植物化石也反映了其在始新世时的亚热 带特征(金建华等, 2008; Yao et al, 2009; 赵炜等, 2009)。现在海南岛距广东雷州半岛仅 $20 \mathrm{~km}$, 中间 的琼州海峡仅深 40-120 m (张虎男和陈伟光, 1987)。琼州海峡曾被认为是在中全新世以后由于海 水入侵形成的连接海南岛与广东的低地(林晓东和 宗永强, 1987; Zhao et al, 2007), 但也有完全不同的 观点, 认为琼州海峡是更新世的一个活动裂谷(张 虎男和陈伟光, 1987; 张虎男, 1996)。古地磁学研究 显示, 在中生代时海南岛的位置比现在高5-6个纬 度, 连接着当时的越南和广西。新生代早期, 随着 北部湾与大陆板块的断裂, 海南岛开始沿哀牢山一 红河断裂带向东南方向移动和旋转, 最终到达现在 的位置(莫宴情和施央申, 1987; Li et al, 1995; Rangin et al, 1995; Liu \& Morinaga, 1999; 付璐露等, 2010; 马云等, 2014)。在海南北部和雷州半岛对应分布有 广泛的火山群, 这些特征也显示在它们之间存在板 块边缘(张虎男, 1990; Yan et al, 2006)。

Zhu (2016)通过比较海南与周边中国广西和广 东以及越南的植物区系, 发现海南的植物区系与越 南相似性最大, 其次是与广西; 在所比较的这些植 物区系中, 有 110 个属仅海南与越南共有, 有 7 个属 仅海南与广东共有。哺乳动物也显示了与植物区系 类似的生物地理格局: 海南与越南的联系最密切; 在生物地理上, 提出海南岛在始新世时期可能曾连 接着越南和广西。

本文的目的并非论证海南岛的起源问题，而是
介绍一些在分布上具有特殊地理意义的植物科和 属, 期望能激发对海南岛起源有兴趣的学者进一步 进行分子生物地理、亲缘地理及遗传多样性等方面 的研究, 为探讨海南岛的起源提供依据。

\section{1 研究方法}

根据邢福武等(2012)的《海南植物物种多样性 编目》和邢福武等(2014)的 《中国热带雨林地区植 物图鉴: 海南植物 I-III》, 选择一些在分布上具有特 殊地理意义的植物科和属, 按APG III系统(APG, 2009; Chase \& Reveal, 2009)和Flora of China (Editorial Committee of Flora of China, 1989-2013)记录 的地理分布处理科属范畴及分布。如果有分类群的 修订性文献资料, 也一并参考。

\section{2 结果}

\section{1 科的分析}

(1)龙脑香科(Dipterocarpaceae)。龙脑香科有 17 属约 550 种, 是一个泛热带分布科, 分布于热带非 洲、热带美洲和热带亚洲, 并以热带亚洲为种的多 样化中心(有13属约472种)。亚洲龙脑香科植物的祖 先可能生长在东冈瓦纳的热带地区(东热带非洲), 于渐新世到达东南亚后迅速分化发展, 并在西马来 西亚形成现在的多样化中心(Ashton, 1982)。中国有 5 属 11 种。这 5 个属均是典型的热带亚洲分布, 并以 西马来西亚为种多样化中心; 而这 11 个种多为大陆 东南亚分布, 少数种类为越南北部至中国西南热带 地区分布。海南岛有龙脑香科植物 2 属 3 种, 分别为 青梅属(Vatica)和坡垒属(Hopea)。青梅属约有65种, 分布区与亚洲龙脑香科一致, 也是以西马来西亚为 现代分布中心。中国的青梅属有 2 个种, 即青梅 (Vatica mangachapoi)和广西青梅(V. guangxiensis)。 青梅是在热带亚洲分布较广的种类, 从马来西亚地 区一直到泰国和越南均有分布, 在中国仅见于海 南。广西青梅分布在云南南部、广西西南部和越南 北部。坡垒属有 100 种, 也是典型热带亚洲分布, 同 样以西马来西亚为现代分布中心。中国境内肯定分 布的种类有 3 种: 狭叶坡垒(Hopea chinensis)分布在 云南东南部、广西西南部和越南北部; 坡垒 $(H$. hainanensis) 和铁凌(H. reticulata) 分布在海南和越南 北部。海南具有的 3 种龙脑香科植物中, 铁凌和狭叶 坡垒分别为与越南北部、广西西南部及云南南部共 
有的局域分布种; 青梅为热带亚洲广布种。从地理 分布格局上看, 海南的这 3 种龙脑香科植物均与越 南和广西西南部相联系。青梅属和坡垒属植物均为 原始热带雨林的高大乔木树种, 均具有较大的、带 翼的果实, 生态学观察显示它们的传播能力很有限, 其种子都是顽拗型, 落地几天就萌发, 并依赖于原 始热带雨林存在和进行扩散(Wen, 2011)。海南这3 种龙脑香科植物的存在意味着海南与越南北部和 广西西南部存在可能的陆地联系。

(2)钩枝藤科(Ancistrocladaceae)。钩枝藤科只 有 1 属约 16 种, 是一个热带亚洲至热带非洲分布科。 该科植物均是热带森林中的木质大藤本(Taylor et al, 2005; Meimberg et al., 2009), 在我国仅有1个种，即 钩枝藤(Ancistrocladus tectorius)。该种从印度经大陆 东南亚分布到马来西亚地区，在我国过去仅见于海 南, 但最近在广西大青山也采到其标本。与龙脑香 科植物类似, 钩枝藤也具有较大的、带翼的果实, 其种子也是顽拗型(咨询西双版纳热带植物园种子 库研究人员), 主要分布在低地常绿森林, 并依赖于 森林生存和进行扩散。该科植物的分布格局也反映 了广西西南部、海南和越南的可能的陆地连接。

(3)单室荣英科(Mastixiaceae)。单室茱英科有2 属27种, 热带亚洲或印度-马来西亚分布, 均为乔 木树种。我国有2属4种。2属即马蹄参属(Diplopanax) 和单室茱英属(Mastixia)。马蹄参属有 2 种, 一种是马 蹄参(D. stachyantus), 分布在云南东南部和越南北 部, 另一种分布在越南。单室茱英属有 25 种, 典型 的热带亚洲分布, 我国有 3 种。五荵单室茱英 $(M$. pentandra)分布于海南、云南南部、中南半岛、印 度东北部和马来西亚, 其原变种分布于云南南部、 中南半岛、印度东北部, 变种单室茱英(M. pentandra subsp. cambodiana) 分布于海南、越南及柬埔寨; 毛叶单室茱英(M. trichophylla)分布于广西西南部和 云南南部; 八荵单室茱英( $M$. euonymoides) 分布于 云南南部、缅甸北部和泰国( $\mathrm{Zhu}, 2004)$ 。从科水平 看, 该科植物为典型热带亚洲分布, 并以马来西亚 为种多样化中心; 它们在中国分布于云南南部、东 南部、广西西南部和海南, 体现了云南南部、广西 西南部和海南的联系。该科植物的果实大, 种子为 顽拗型, 须在森林中生存和进行扩散。从系统进化 上来看(朱伟华和向其柏, 2001), 马蹄参属是该科植 物的原始类群, 存在于云南东南部和越南北部, 其
他相对演化的类群存在于云南南部、东南部、广西 西南部、海南和东南亚。这种格局也反映了广西西 南部、海南和越南可能的陆地连接。

(4)肉豆冦科(Myristicaceae)。肉豆冦科植物有 20 属约 500 种, 是一个泛热带分布科, 分布于热带 非洲、热带美洲和热带亚洲，并以热带亚洲为种的 多样化中心。中国有3属10种, 即红光树属(Knema)、 肉豆冦属(Myristica) 和风吹楠属(Horsfieldia)。中国 的这 3 个属都是热带亚洲分布属, 并以热带亚洲为 种多样化中心。红光树属在中国有6种，分布于云南 热带地区; 肉豆冦属在我国仅1种，产云南南部; 风 吹楠属在我国有3种，大叶风吹楠(H. kingii)和风吹 楠(H. amygdalina)产云南南部、东南部、广西西南 部和海南, 云南风吹楠(H. prainii)产云南南部。肉豆 冦科植物均为原始热带雨林的乔木树种，它们均具 有较大果实和顽拗型种子, 并依赖于原始热带雨林 存在和进行扩散。这种格局的形成同样反映了广西 西南部、海南和越南的可能的陆地连接。

(5)五膜草科(Pentaphragmaceae)。五膜草科是 热带森林下的一个草本植物科, 只有 1 属, 约 25 种, 热带亚洲分布。中国有2种，五膜草(Pentaphragma sinense)特产云南南部至越南北部, 另一种直序五 膜草(P. spicatum) 特产广西西南部、广东西南部和海 南。这种格局也反映了广西西南部、海南和越南的 可能的陆地连接。

\section{2 属的分析}

(1)油丹属(Alseodaphne)。樟科(Lauraceae)常绿 乔木，热带亚洲分布。中国有 10 种，其中 7 种为特有 种, 6 种为云南南部、东南部特有。长柄油丹 $(A$. petiolaris)和毛叶油丹(A. andersonii)为云南南部至 东南亚分布，皱皮油丹(A. rugosa) 为海南和云南东 南部特有, 油丹(A. hainanensis)为海南和越南北部 特有。

(2)细子龙属(Amesiodendron)。无患子科(Sapindaceae) 常绿乔木, 热带亚洲分布。单种属, 即细子 龙(A. chinense), 在中国产云南东南部、广西西南部 和海南。

(3)蒙蒿子属(Anaxagorea)。番荔枝科(Annonaceae)灌木或小乔木, 热带亚洲-热带美洲分布。中 国有1种, 即蒙蒿子(A. luzonensis), 分布于广西西南 部和海南。

(4)海南椴属(Diplodiscus)。椴树科(Tiliaceae)乔 
木树种, 热带亚洲分布。中国特有 1 种, 即海南椴 $(D$. trichospermus), 产广西西南部和海南。

(5)龙血树属(Dracaena)。百合科(Liliaceae, FOC) 或天门冬科(Asparagaceae, APG III)乔木或灌木, 热 带亚洲至热带非洲分布。中国有6种，分布于云南西 南部至东南部、广西西南部和海南。柬埔寨龙血树 (D. cambodiana) 分布于印度支那、云南南部、东南 部、广西西南部和海南, 遗传多样性研究显示, 它 可能在第三纪起源于印度支那, 随喜马拉雅的隆升 而扩散和在遗传多样性上分化, 形成现在的分布格 局(Zhao et al, 2013)。

(6)长柱山丹属(Duperrea)。茜草科(Rubiaceae) 灌木, 中南半岛至中国热带地区分布。单种属, 即长 柱山丹(D. pavettifolia), 在中国产云南南部、广西西 南部和海南。

(7)崖藤属(Albertisia)。防己科(Menispermaceae) 木质大藤本, 热带亚洲-热带非洲分布。单种属, 即 崖藤(Albertisia laurifolia), 在中国分布于云南南部、 广西西南部、海南和越南北部。

(8) 山檨子属(Buchanania)。漆树科(Anacardiaceae)乔木树种, 热带亚洲-热带非洲分布。中国大 陆有3种, 云南山檨子(B. yunnanensis)特产于云南 南部, 小叶山榚子(B. microphylla) 见于海南, 豆腐 果(B. latifolia)分布于云南南部和海南。

(9)蕉木属(Chieniodendron)。番荔枝科(Annonaceae) 乔木树种, 中国特有。单种属, 即蕉木 $(C$. hainanense), 产广西西南部和海南。

(10)牛栓藤属 (Connarus)。牛栓藤科 (Connaraceae) 木质大藤本, 泛热带分布。中国产2种, 牛栓 藤(C. paniculatus) 产海南, 云南牛栓藤 (C. yunnanensis)产云南南部和广西西南部。

(11)五桠果属(Dillenia)。五桠果科(Dilleniaceae) 乔木树种, 旧世界热带分布。中国产3种, 五桠果 $(D$. indica)产云南南部和广西西南部, 大花五桠果 $(D$. turbinata)产云南南部、广西西南部和海南, 小花五 桠果(D. pentagyna)分布于云南南部和海南。

(12) 琼榄属 (Gonocaryum)。茶荣莫科 (Icacinaceae)乔木树种, 热带亚洲分布。中国大陆产1种, 即琼榄(G. lobbianum), 分布于云南南部和海南。

(13)牛筋果属(Harrisonia)。苦木科(Simaroubaceae)攀援有刺灌木, 旧世界热带分布。中国产1种, 即牛筋果(H. perforata), 分布于广西西南部和海南。
(14)大风子属(Hydnocarpus)。大风子科(Flacourtiaceae)乔木树种，热带亚洲分布。中国产3种，其 中大叶龙角 $(H$. annamensis) 和泰国大风子 $(H$. anthelminthicus)分布于云南南部和广西西南部, 海 南大风子(H. hainanensis) 分布于云南南部、广西西 南部及海南。

(15)厚皮树属(Lannea)。漆树科(Anacardiaceae) 乔木树种, 热带亚洲-热带非洲分布。中国产1种, 即厚皮树 (L. coromandelica), 分布于云南南部、广西 西南部、广东西南部和海南。

(16)鳞花木属(Lepisanthes)。无患子科(Sapindaceae)乔木树种，旧世界热带分布。中国产8种，其中 云南和缅甸特有 2 种, 即大叶鳞花木(L. browniana) 和 心叶鳞花木 (L. basicardia); 广西西南部特有 1 种, 即茎花赤才(L. cauliflora), 海南特有3种, 即赛木患 (L. oligophylla), 鳞花木(L. hainanensis) 和爪耳木 $(L$. unilocularis); 云南南部、广西西南部产滇赤才 $(L$. senegalensis), 广西西南部、广东西南部和海南产赤 才(L. rubiginosa)。

(17)紫荆木属(Madhuca)。山榄科(Sapotaceae) 乔木树种, 热带亚洲-热带澳洲分布。中国产2种, 紫荆木(M. pasquieri)分布于云南东南部、广西西南 部、广东西南部和越南北部, 海南紫荆木 $(M$. hainanensis)特产海南。

(18)铁线子属(Manilkara)。山榄科(Sapotaceae) 灌木, 泛热带分布。中国产1种, 即铁线子(M. hex$a n d r a)$, 分布于广西西南部和海南。

(19)胶核木属(Myxopyrum)。木犀科(Oleaceae) 攀援灌木, 热带亚洲分布。中国产2种, 均分布于海 南。海南胶核木(M. pierrei)分布于海南、越南、老 挝和泰国; 阔叶胶核木 (M. smilacifolium) 分布于海 南和印度支那半岛各国。这种分布格局用海南曾经 与越南连接可以解释。

(20)铁青树属(Olax)。铁青树科(Olacaceae)乔木 树种，旧世界热带分布。中国大陆产 3 种，其中铁青 树 (O. imbricata) 产海南, 疏花铁青树 (O. austrosinensis)分布于广西西南部和海南, 尖叶铁青树 (O. acuminata)分布于云南。

(21) 假韶子属 (Paranephelium)。无患子科 (Sapingdaceae)乔木树种，热带亚洲分布。中国产2 种, 其中海南假韶子( $P$. hainanense)特产海南, 云南 假韶子(P. hystrix)特产云南和缅甸。 
(22)肖榄属(Platea)。茶荣英科(Icacinaceae)乔木 树种, 热带亚洲分布。中国产2种, 其中东方肖榄 $(P$. parvifolia)特产海南, 阔叶肖榄(P. latifolia)产云南南 部、广西西南部、广东西南部和海南。

(23)钩叶藤属(Plectocomia)。棕㭣科(Palmae)木 质大藤本, 热带亚洲分布。中国产3种, 其中小钩叶 藤(P. microstachys)特产海南, 高地钩叶藤( $P$. himalayana)产云南, 钩叶藤(P. pierreana)产云南南部、广 西西南部、广东西南部。

(24)多香木属(Polyosma)。鼠刺科(Iteaceae)乔木 树种, 热带亚洲至澳洲分布。中国产 1 种, 即多香 木(P. cambodiana), 分布于云南南部、广西西南部 和海南。

(25)桃榄属(Pouteria)。山榄科(Sapotaceae)乔木 树种，泛热带分布。中国产2种，其中桃榄(P. annamensis)特产广西西南部、越南北部和海南; 龙果 (P. grandifolia)产云南南部。

(26)翅苹婆属(Pterygota)。梧桐科(Sterculiaceae) 大乔木, 热带亚洲-热带非洲分布。中国有 1 种, 即 翅苹婆(P. alata), 产云南南部和海南。

(27)染木树属(Saprosma)。茜草科(Rubiaceae) 灌木, 热带亚洲分布。中国产5种, 其中2种分布于 云南南部和海南, 即厚梗染木树(S. crassipes)和染 木树(S. ternata), 云南染木树(S. henryi)特产云南, 琼岛染木树(S. merrillii)和海南染木树(S. hainanensis)特产海南。

(28)硬核属(Scleropyrum)。檀香科(Santalaceae) 乔木, 热带亚洲分布。中国产1种，即硬核(S.wallichianum), 分布于云南南部、广西西南部和海南。

(29) 十字菅苔属 (Stauranthera)。苦苣苔科 (Gesneriaceae) 多年生草本植物, 热带亚洲分布, 约 10 种。中国有 2 种, 其中十字菅苔(S. umbrosa) 分布于 云南南部、广西西南部和海南。大花十字苣苔 $(S$. grandiflora)分布于云南南部和海南。该属植物为典 型的热带雨林下的草本植物(朱华等, 1996)。

(30)油果樟属(Syndiclis)。樟科(Lauraceae)乔木 树种, 中国准特有分布。该属植物有 10 种, 其中 9 种 特产中国。云南东南部特产 4 种, 即麻栗坡油果樟(S. marlipoensis)、屏边油果樟(S. pingbienensis)、西畴 油果樟(S. sichourensis)和富宁油果樟 (S. fooningensis); 广西西南部特产广西油果樟(S. kwangsiensis); 贵州西南部特产安龙油果樟(S. anlungensis);
海南特产 2 种, 即乐东油果樟(S. lotungensis)和油果 樟(S. chinensis)。该属植物在亲缘地理关系上对探讨 海南岛的起源非常有价值。

(31)三棱栋属(Trigonobalanus)。壳斗科(Fagaceae)的原始类群，热带亚洲-热带美洲分布。该属植 物有3种，中国有2种，三棱柇(T. doichangensis)产云 南南部, 轮叶三棱栋(T. verticillata)产云南南部和海 南(Ng \& Lin, 2008, 朱华和周仕顺, 2017)。这2种植物 被认为是栎属(Quercus)和水青冈属(Fagus)植物的 祖先(Nixon \& Crepet, 1989), 对它们进行深入研究将 对探讨海南岛的起源具有重要的生物地理学意义。

(32)滑桃树属(Trewia)。大戟科(Euphorbiaceae) 大乔木, 热带亚洲分布。单种属, 即滑桃树 $(T$. nudiflora), 在中国产云南南部、广西西南部和海南。

(33)割舌树属(Walsura)。楝科(Meliaceae)乔木 树种, 热带亚洲分布。中国有2种, 即割舌树 $(W$. robusta) 和越南割舌树( W. pinnata), 均产云南南部、 广西西南部和海南。

(34)保亭花属(Wenchengia)。唇形科(Lamiaceae) 灌木。单种属, 即保亭花(W. alternifolia), 原认为特 产海南，现在越南也有发现。

(35)刺榄属(Xantolis)。山榄科(Sapotaceae)乔木, 热带亚洲分布。中国产 4 种。云南特产 2 种，即滇刺 榄(X. stenosepala)和瑞丽刺榄(X. shweliensis), 海南 特产 2 种, 即啄果刺榄 $(X$. boniana var. rostrata)和琼 刺榄 $(X$. longispinosa)。

(36)齐头线属(Zippelia)。胡椒科(Piperaceae)原 始草本植物, 热带亚洲分布。单种属, 即齐头线 $(Z$. begoniaefolia), 中国产云南南部、广西西南部和海南 的热带雨林林下。

\section{3 讨论}

上面所列举的这些科和属包括了乔木、灌木、 藤本、草本各种生活型，其种类分布均显示了云南 南部、东南部、广西西南部和海南的分布格局，广 泛存在于这些地区的热带植被中。大部分乔木树种 均具有较大果实和顽拗型种子，而研究显示这类树 种一般都依赖于原始森林存在和进行扩散。这种分 布格局形成的最好解释是广西西南部、海南和越南 北部曾存在可能的陆地连接。除乔木树种外，其他 的灌木、藤本、草本植物生活型种类也可用这些地 区的历史连接最好地给予解释。在海南岛，除文中 
列举的这些科和属外, 还有更多这样的类群存在。

海南岛为陆地起源而非火山岛起源, 这一点已 是共识, 但海南岛是一直连接着广东大陆, 还是在 始新世时仍可能连接着越南北部和广西, 后来随着 喜马拉雅的隆升及印度支那地质板块向东南的逃 逸, 发生了向东南的移动和旋转, 最终到达了现在 的位置, 仍有争议。古地磁学研究已揭示在中生代 时海南岛是在一个连接着越南和广西、比现在高 5-6个纬度的位置, 新生代早期, 随着北部湾裂开, 海南岛开始沿哀牢山-红河断裂带发生了向东南的 移动和旋转, 最终到达了现在的位置。在植物区系 上, 海南植物区系与越南植物区系的相似性最大, 其次是广西植物区系。在哺乳动物区系上, 海南与 越南的联系最密切, 例如, 海南坡鹿(Cervus eldi)、 海南(越南)长臂猿(Hylobates concolor)的存在都显 示了与越南及印度支那联系密切, 在生物地理学上 支持了海南岛曾与越南和广西有陆地连接的观点。 在第四纪以来, 由于海平面的升降, 海南岛可能发 生了多次与广东雷州半岛的连接, 这使海南的生物 区系变得复杂化了。文中列举的这些科和属及其种 类均显示了越南、云南、广西西南部及海南的分布 格局，非常值得进行深入的分子生物地理、亲缘地 理及遗传多样性等研究, 以共同探讨海南岛的起源 这一重要的学术问题。希望有兴趣的科研人员能通 过列举的这些科和属的情况获得思路, 利用分子生 物学等方法去深入研究, 最终解决这一问题。

\section{参考文献}

APG (2009) An update of the Angiosperm Phylogeny Group classification for the orders and families of flowering plants: APG III. Botanical Journal of the Linnean Society, 161, $105-121$.

Ashton PS (1982) Dipterocarpaceae. In: Flora Malesiana, Series I, 9(2) (ed. van Steenis CGGJ). National Herbarium of the Netherlands, The Netherlands.

Chase MW, Reveal JL (2009) A phylogenetic classification of the land plants to accompany APG III. Botanical Journal of the Linnean Society, 161, 122-127.

Editorial Committee of Flora of China (1989-2013) Flora of China, Vols. 1-25. Science Press, Beijing \& Missouri Botanical Garden Press, St Louis.

Francisco-Ortega J, Wang ZS, Wang GF, Xing FW, Liu H, Xu $\mathrm{H}, \mathrm{Xu}$ WX, Luo YB, Song XQ, Gale S, Boufford DE, Maunder M, An SQ (2010a) Endemic seed plant species from Hainan Island: a checklist. Botanical Review, 76, 295345.

Francisco-Ortega J, Wang ZS, Wang GF, Xing FW, Liu H, Xu
H, Xu WX, Luo YB, Song XQ, Gale S, Boufford DE, Maunder M, An SQ (2010b) Seed plant endemism on Hainan Island: a framework for conservation actions. Botanical Review, 76, 346-376.

Fu LL, Shen ZY, He L, Dong CW, Cheng XG, Tang LM, Yang SF (2010) Cretaceous paleomagnetic results from Hainan Island and its tectonic implications. Acta Geologica Sinica, 84, 183-194. (in Chinese with English abstract) [付璐露, 沈忠悦, 贺丽, 董传万, 程晓敢, 唐立梅, 杨树锋 (2010) 海南岛白严纪古地磁结果及其构造地质意义. 地质学报, 84, 183-194.]

Guangdong Institute of Botany (1976) Vegetation of Guangdong, pp. 41-97. Science Press, Beijing. (in Chinese) [广东 植物研究所 (1976) 广东植被, 41-97页. 科学出版社, 北 京.]

Jin JH, Shen RJ, Liao WB (2008) Analysis of the families of Cenozoic spermatophytic flora in Hainan Island. Acta Botanica Boreali-Occidentalia Sinica, 28, 2125-2131. (in Chinese with English abstract) [金建华, 沈如江, 廖文波 (2008) 海南岛新生代种子植物区系科的多样性分析. 西 北植物学报, 28, 2125-2131.]

Li ZX, Metcalfe I, Wang XF (1995) Vertical-axis block rotations in southwestern China since the Cretaceous: new Paleomagnetic results from Hainan Island. Geophysical Research Letters, 22, 3071-3074.

Lin XD, Zong YQ (1987) More on the origin of the Qiongzhou Strait. Tropical Geography, 7, 338-345. (in Chinese with English abstract) [林晓东, 宗永强 (1987) 再论琼州海峡 成因. 热带地理, 7, 338-345.]

Liu YY, Morinaga H (1999) Cretaceous palaeomagnetic results from Hainan Island in South China supporting the extrusion model of Southeast Asia. Tectonophysics, 301, 133-144.

Ma Y, Li SZ, Liu X, Zhao SJ, Yu S, Wang XF, Zhang BK (2014) Formation mechanism of the Beibuwan Basin, South China. Journal of Jilin University (Earth Science Edition), 44, 1727-1736. (in Chinese with English abstract) [马云, 李三忠, 刘金鍂, 赵淑娟, 余珊, 王霄飞, 张丙坤 (2014) 华南北部湾盆地的形成机制. 吉林大学学报(地球科学 版), 44, 1727-1736.]

Meimberg H, Rischer H, Turini FG, Chamchumroon V, Dreyer M (2009) Evidence for species differentiation within the Ancistrocladus tectorius complex (Ancistrocladaceae) in Southeast Asia: a molecular approach. Plant Systematics and Evolution, 284, 77-98.

Mo YQ, Shi YS (1987) Palaeomagnatic study and tectonic evolution of Hainan Terrane and its vicinal continental coast the Late Mesozoic to Cenozoic. Journal of Nanjing University (Natural Science Edition), 23, 521-532. (in Chinese with English abstract) [莫宴情, 施央申 (1987) 海南岛地 体及其毗邻陆缘晚中生代-新生代古地磁研究和构造演 化. 南京大学学报(自然科学版), 23, 521-532.]

Ng SC, Lin JY (2008) A new distribution record for Trigonobalanus verticillata (Fagaceae) from Hainan Island, South China. Kew Bulletin, 63, 341-344.

Nixon KC, Crepet WL (1989) Trigonobalanus (Fagaceae): taxonomic status and phylogenetic relationships. American 
Journal of Botany, 76, 828-841.

Rangin C, Klein M, Roques D, Pichon XL, Le VT (1995) The Red River fault system in the Tonkin Gulf, Vietnam. Tectonophysics, 243, 209-222.

Taylor CM, Gereau RE, Walters GM (2005) Revision of Ancistrocladus Wall. (Ancistrocladaceae). Annals of the Missouri Botanical Garden, 92, 360-399.

Wen B (2011) Changes in the moisture and germination of recalcitrant Hopea mollissima seeds (Dipterocarpaceae) in different desiccation regimes. Seed Science and Technology, 39, 214-218.

Wu TL, Xing FW, Ye HG, Li ZX, Chen BH (1996a) Study on the spermatophytic flora of South China Sea Islands. Journal of Tropical and Subtropical Botany, 4(1), 1-22. (in Chinese with English abstract) [吴德邻, 邢福武, 叶华谷, 李泽贤, 陈炳辉 (1996a) 南海岛屿种子植物区系地理的研究. 热 带亚热带植物学报, 4(1), 1-22. ]

Wu TL, Xing FW, Ye HG, Li ZX, Chen BH (1996b) Study on the spermatophytic flora of South China Sea Islands (continue). Journal of Tropical and Subtropical Botany, 4(2), 1-11. (in Chinese with English abstract) [吴德邻, 邢福武, 叶华谷, 李泽贤, 陈炳辉 (1996b) 南海岛屿种子植物区 系地理的研究(续). 热带亚热带植物学报, 4(2), 1-11.]

Wu ZY, Sun H, Zhou ZK, Li DZ, Peng H (2010) Floristics of Seed Plants from China. Science Press, Beijing. (in Chinese) [吴征镒, 孙航, 周浙昆, 李德铢, 彭华 (2010) 中国种子 植物区系地理. 科学出版社, 北京.]

Wu ZY, Wu SG (1996) A proposal for a new floristic kingdom (realm): the Asiatic kingdom, its delineation and characteristics. In: Floristic Characteristics and Diversity of East Asian Plants (eds Zhang AL, Wu SG). China Higher Education Press, Beijing; Springer-Verlag, Berlin Heidelberg.

Xing FW, Chen HF, Qin XS, Zhang RJ, Zhou JS (2014) Illustrated Handbook of Plants in Tropical Rainforest Area of China: Plants of Hainan. Vols. I-III. Huazhong Science and Technology Press, Wuhan. (in Chinese) [邢福武, 陈红锋, 秦新生, 张荣京, 周劲松 (2014) 中国热带雨林地区植物 图鉴: 海南植物 (I-III). 华中科技大学出版社, 武汉.]

Xing FW, Zhou JS, Wang FG, Zeng QW, Yi QF, Liu DM (2012) Inventory of Plant Species Diversity of Hainan. Huazhong Science and Technology Press, Wuhan. (in Chinese) [邢福武，周劲松，王发国，曾庆文，易绮斐，刘东明 (2012) 海南植物物种多样性编目. 华中科技大学出版社, 武汉.]

Yan P, Deng H, Liu HL, Zhang ZR, Jiang YK (2006) The temporal and spatial distribution of volcanism in the South China Sea region. Journal of Asian Earth Sciences, 27, 647-659.

Yang XB (2013) Plant List of Hainan. Science Press, Beijing. (in Chinese) [杨小波 (2013) 海南植物名录. 科学出版社, 北京.]

Yao YF, Bera S, Ferguson DK, Mosbrugger V, Paudayal KN, Jin JH, Li CS (2009) Reconstruction of paleovegetation and paleoclimate in the Early and Middle Eocene, Hainan Island, China. Climatic Change, 92, 169-189.

Zhang CC, Liu LF (1983) Angiosperma flora of Hainan. Acta Scientiarum Naturalium Universitatis Sunyatseni, (3), 67-
73. (in Chinese with English abstract) [张超常, 刘兰芳 (1983) 海南岛被子植物区系. 中山大学学报(自然科学 版), (3), 67-73.]

Zhang HD (2001) The diversity of the Hainan flora. Ecologic Science, 20, 1-9. (in Chinese with English abstract) [张宏达 (2001) 海南植物区系的多样性. 生态科学, 20, 1-9.]

Zhang HN (1996) Volcanism marks for rift valley of Qiongzhou strait. Seismological and Geomangnetic Observation and Research, 17(4), 42-50. (in Chinese with English abstract) [张虎男 (1996) 琼州海峡裂谷成因的火山活动标 志. 地震地磁观测与研究, 17(4), 42-50]

Zhang HN (1990) Basic characteristics of Cenozoic volcanism in coastal area of South China. Northeastern Seismological Research, 6(1)，63-75. (in Chinese) [张虎男 (1990) 华南 沿海新生代火山活动的基本特征. 东北地震研究, 6(1), 63-75.]

Zhang HN, Chen WG (1987) A search for the cause of Qiongzhou Strait. Acta Oceanologica Sinica, 9, 594-602. [张虎男, 陈伟光 (1987) 琼州海峡成因初探. 海洋学报, 9, 594-602.]

Zhao HT, Wang LR, Yuan JY (2007) Origin and time of Qiongzhou Stait. Marine Geology \& Quaternary Geology, 27(2), 33-40.

Zhao JL, Zhang L, Dayanandan S, Nagaraju S, Liu DM, Li QM (2013) Tertiary origin and Pleistocene diversification of dragon blood tree (Dracaenacam bodiana-Asparagaceae) populations in the Asian tropical forests. PLoS ONE, 8, e60102.

Zhao W, Shen RJ, Liao WB, Jin JH (2009) Eocene Palynoflora from Changchang Basin, Hainan Island. Journal of Jilin University (Earth Science Edition), 39, 379-396. (in Chinese with English abstract) [赵炜，沈如江，廖文波，金建 华 (2009) 海南岛长昌盆地始新世狍粉植物区系. 吉林 大学学报(地球科学版), 39, 379-396.]

Zhu H (2004) Biogeographical implications of some plant species from a tropical montane rain forest in southern Yunnan. Chinese Geographical Science, 14, 221-226.

Zhu H (2016) Biogeographical evidences help revealing the origin of Hainan Island. PLoS ONE, 11, e0151941.

Zhu H, Roos MC (2004) The tropical flora of southern China and its affinity to Indo-Malesian flora. Telopea, 10, 639-648.

Zhu H, Wang H, Li BG (1996) Stauranthera, a new record from China. Acta Botanica Yunnanica, 18, 144. (in Chinese) [朱华, 王洪, 李保贵 (1996) 十字苣苔属一新记录种. 云 南植物研究, 18, 144.]

Zhu H, Zhou SS (2017) A primitive Cupuliferae plant Trigonobalanus verticillata found in Xishuangbanna, Yunnan and its biogeographical significance. Plant Science Journal, 35(2), 205-206. (in Chinese with English abstract) [朱华, 周仕顺 (2017) 壳斗科原始植物轮叶三棱栎在云南西双版纳的发 现及其生物地理意义. 植物科学学报, 35(2), 205-206.]

Zhu WH, Xiang QB (2001) The origin and distribution of genus Diplopanax Hand.-Mazz. Journal of Nanjing Forestry University, 25(1), 35-38. (in Chinese with English abstract) [朱伟华, 向其柏 (2001) 马蹄参属的起源和地理分布. 南京林业大学学报, 25(1), 35-38. ]

(责任编辑：黄祥忠) 